\title{
Appropriateness of colonoscopy in Cocody teaching hospital center in 2010: A prospective study using criteria established by the European panel on the appropriateness of gastrointestinal endoscopy (EPAGE)
}

\author{
Constant Assi*, Marie Jeanne Lohouès-Kouacou, Emile Allah-Kouadio, Christian Jomo Njossu, \\ Anassi Jean-Baptiste Okon, Stanislas Doffou, Siaka Koné, Ganda Soumaré, Amadou Koné, \\ Amadou Ouattara, Dramane Soro, Mamadou Diakité, Benoît-Mathieu Camara
}

Department of Gastroenterology, Faculty of Medical Sciences, Cocody Teaching Hospital Center, Abidjan, Côte d’Ivoire Email: assiconstant@yahoo.fr

Received 22 July 2012; revised 25 August 2012; accepted 3 September 2012

\begin{abstract}
Aims: 1) To assess the feasibility of EPAGE criteria in clinical practice; 2) To assess appropriateness colonoscopy using EPAGE criteria; 3) To compare colonoscopy appropriateness and endoscopic lesions. Method: Hundred thirty-nine consecutive patients explored by colonoscopy were included. The appropriateness of colonoscopy was evaluated by EPAGE criteria. Results: EPAGE criteria were applicable among 127 patients (91\% of the cases). Colonoscopies were appropriate, uncertain and inappropriate in respectively $40 \% ; 27 \%$ and $24 \%$ of the cases. Rate of abnormal colonoscopies was significantly different between the 3 groups $(p=0.03)$. Cancers were diagnosed exclusively in the groups with appropriate and uncertain colonoscopies (11\% and $5 \%)$. Colonic adenomas were observed in the three groups (appropriate $(7 \%)$, uncertain $(5 \%)$ and inappropriate $(6 \%))$. Subjects with uncertain indication were older (58.25 years; $p=0.035$ ). Conclusion: EPAGE criteria are feasible in clinical practice in Cocody's teaching hospital center. Colonoscopies are generally appropriate in our hospital. However, within sight of the significant number of normal colonoscopies and discovered lesions in uncertain indication, colonoscopy cannot concern exclusively calculation of a score of appropriateness.
\end{abstract}

Keywords: Colonoscopy; Appropriateness; EPAGE Score; Colorectal Cancer; Côte d'Ivoire

\section{INTRODUCTION}

In Côte d'Ivoire, Attia et al. [1] reported that about 40\% "Corresponding author. of general medical consultations, $73 \%$ of those of gastroenterology and $30 \%$ of hospitalizations were motivated by colonic symptoms. According to Camara et al. [2], although these symptoms are mostly functional, it was observed increasingly organic diseases including colorectal, polyps and cancer. Several studies conducted in ivorian hospitals [3-6], estimated the frequency of endoscopic polyps and colorectal cancers of $3 \%$ to $4 \%$. The importance of colonoscopy in colorectal cancer screening and surveillance is established [7,8]. However it is not innocuous $[9,10]$. It can be a source of morbidity and/or death-and it is binding for the patient (pain and bowel preparation). In poor countries, its cost can be an obstacle to its realization. In 1999, a group of European experts, the European panel on the Appropriateness of Gastrointestinal Endoscopy, developed a set of criteria using the RAND appropriateness. Based on a detailed analysis of the literature and expert opinions, the experts established 12 "principles" indications for colonoscopy (Table 1) and presented 309 possible scenarios describing individual clinical situation. Each scenario was assigned a score of 1 to 9 according to the degree of pertinence $[11,12]$.

It is therefore necessary to rationalize colonoscopy prescription taking into account the cost/benefit ratio. To this effect, several experts met to rationalize the prescription of colonoscopy by issuing recommendations and consensus on its indications [11]. Several studies have confirmed the applicability and appropriateness of this score [12-14].

In Côte d'Ivoire, no study has assessed the appropriateness of indications for colonoscopy. The aim of our study was to evaluate the applicability of criteria of EPAGE to the practice of colonoscopy at the university hospital (UH) in Cocody, evaluate using these criteria the 
Table 1. Major indication according to the EPAGE criteria.
Iron deficiency anemia (malabsorption excluded)
Rectal bleeding (chronic inflammatory bowel disease excluded)
and without positive blood culture, and without abdominal pain
Absence of anemia, bleeding, risk factors for colorectal cancer
Evaluation of known ulcerative disease
Evaluation of Known Crohn's disease
Screening for colorectal disease in patients with known ulcerative colitis
Screening for colorectal disease in patients with known Crohn's disease
Surveillance after polypectomy or curative surgery for colorectal cancer
Screening for colorectal cancer

Unexplained abdominal pain $>2$ months, without chronic inflammatory bowel disease, without anemia, and without positive blood culture

Transit disorder (mainly constipation) > 2 months, without chronic inflammatory bowel disease, without anemia,

Unexplained diarrhea (infection excluded, malabsorption excluded, and without, and without chronic inflammatory bowel disease).

Other indications: lesions on barium enema or at rectosigmoidy, preoperative colonoscopy, positive blood culture,

fulminant colitis, acute diverticulosis, endometriosis, unexplained weight loss

appropriateness of the indications of colonoscopy and their correlation with endoscopic findings.

\section{PATIENTS AND METHOD}

It was a prospective cross-sectional observational study. The study was conducted during a period of six months (December 1, 2009 to May 31, 2010) in the endoscopy unit of the Division of Gastroenterology teaching Hospital in Cocody. All patients who underwent colonoscopy during the study period were consecutively recruited after oral informed consent to participate in the study. Non-inclusion criteria were: incomplete colonoscopy or therapeutic colonoscopy, preoperative assessment, patient refusal to participate in the study. Parameters of the study were done using a questionnaire completed by the endoscopist. All six endoscopists of the unit had agreed to participate in the study. The variables studied were: sex, age, medical history, type of patient (outpatient or hospitalized), indication for colonoscopy (when multiple indications, that leading the highest EPAGE score was used), specialty of the prescriber, further colonic explorations before colonoscopy and lesions found. The appropriateness of each indication was evaluated using EPAGE I score available at www.EPAGE.ch. Each indication of colonoscopy was assigned an appropriateness score from 1 to 9. Colonoscopy was appropriate if the score was 7 to 9 and inappropriate between 1 and 3. The appropriateness of the colonoscopy was uncertain for a score between 4 and 6 . The score was inapplicable when indication was not included in any of the 309 scenarios provided by the site of EPAGE. The results of endoscopic and histological colonic lesions were collected.
Data were collected and analyzed using Epi Data analysis 3.0. The chi-square test and Student test were respectively used to analyze qualitative and quantitative variables. The significance level of the test was set at 5\%.

\section{RESULTS}

We received 147 patients. Among them, eight persons were excluded (indication of polypectomy in 4 cases and incomplete colonoscopy for poor preparation in four other cases). We retained 139 patients. The characteristics of patients are presented in Table 2. The age of our patients ranged from six months to 86 years with a mean age of 49 years (standard deviation 14). The sex ratio was 1.04 .

1) Applicability of EPAGE criteria and appropriateness of the indications for colonoscopy

The EPAGE criteria were not applicable in 9\% of cases $(n=12)$. Table 3 shows colonoscopies that did not meet the EPAGE criteria.

The EPAGE criteria were applicable in 127 patients (91\% of cases). The distribution of theirs indications is presented in Table 4.

Other indications not specified in Table 4 were: suspicious of left bowel disease in barium enema, suspicious of lesion caecum disease; rectal and sigmoid stenosis. Suspicion of left colonic lesion in abdominal Computer Tomography. Any indication of colorectal cancer screening, control after curative surgery for colorectal cancer or colonoscopy after positive Hemoccult was found. The proportion of colonoscopies $(\mathrm{p}=0.03)$ considered appropriate, uncertain and inappropriate was respectively $40 \%(n=56), 27 \%(n=38)$ and $24 \%(n=33)$. There was 
Table 2. Demographic characteristics.

\begin{tabular}{|c|c|c|c|c|c|}
\hline \multirow[t]{2}{*}{ Parameter } & \multicolumn{5}{|c|}{ Indications of colonoscopies according to the criteria of EPAGE } \\
\hline & Appropriate & Uncertain & Inappropriate & Non-applicable & $\mathrm{p}$ \\
\hline Effective & $56(40 \%)$ & $38(27 \%)$ & $33(24 \%)$ & $12(9 \%)$ & \\
\hline Mean age (yrs) & $58 \pm 12$ & $45 \pm 14$ & $37 \pm 11$ & $38 \pm 12$ & 0.03 \\
\hline Male/female & $29 / 27$ & $17 / 21$ & $16 / 17$ & $6 / 6$ & 0.86 \\
\hline Referring Physician & & & & & 0.01 \\
\hline General practitioner & $5(9 \%)$ & $7(18.4 \%)$ & $5(15 \%)$ & $6(50 \%)$ & \\
\hline Gastroenterologist & $37(66 \%)$ & $18(47.4 \%)$ & $20(61 \%)$ & $5(42 \%)$ & \\
\hline Other & 10 (25\%) & 13 (34.2\%) & 8 (24\%) & $1(8 \%)$ & \\
\hline
\end{tabular}

Table 3. Colonoscopies that did not meet the EPAGE criteria.

\begin{tabular}{lc}
\hline Indications & $\mathrm{n}=12$ \\
\hline Search for primary tumor (liver metastases) & 4 \\
Anal fissure & 1 \\
Anal pain & 1 \\
Assessment of a mesenteric tumor & 1 \\
Assessment of a spondylarthropathy & 1 \\
Assessment of an ASCUS & 1 \\
Incontinence to gas & 1 \\
Melena without prior gastroscopy & 1 \\
Assessment of mass of RIF* without prior ultrasonography & 1 \\
\hline
\end{tabular}

"ASCUS = Atypical squamous cells of undetermined significance. RIF = Right iliac fossa.

Table 4. Distribution of indications for colonoscopy with the EPAGE criteria applicable.

\begin{tabular}{lccc}
\hline Indication & Appropriate $\mathrm{n}=56 \mathrm{n}(\%)$ & Uncertain $\mathrm{n}=38 \mathrm{n}(\%)$ & Inappropriate $\mathrm{n}=33 \mathrm{n}(\%)$ \\
\hline Control after polypectomy & $0(0)$ & $1(3)$ & $1(3)$ \\
Abdominal pain & $3(5)$ & $16(42)$ & $13(39)$ \\
Constipation/diarrhea & $9(16)$ & $5(13)$ & $18(54)$ \\
Chronic diarrhea & $4(7)$ & $0(0)$ & $0(0)$ \\
Hematochezia & $21(38)$ & $14(37)$ & $0(0)$ \\
Iron deficiency anemia & $3(5)$ & $1(3)$ & $0(3)$ \\
Unexplained loss mass & $7(13)$ & $0(0)$ & $0(0)$ \\
Assessment of abdominal mass & $3(5)$ & $0(0)$ & $0(0)$ \\
Assessment of ulceratis colitis & $0(0)$ & $0(0)$ & $0(0)$ \\
Other indications & $6(11)$ & & 0 \\
\hline
\end{tabular}

no significant difference between proportion of men and women in the 3 groups ( $p=0.68$ ). Patients in the appropriate group were significantly older $(p<0.0001)$ than the other two groups. Thirty-three colonoscopies were considered inappropriate. In 31 cases, the aim was to abdominal pain and/or constipation in a patient under 
fifty years without risk factors for colorectal cancer and without any prior exploration by non-invasive exams. A case of control after polypectomy in a too short time and a case of exploration of microcytic hypochromic anemia without prior gastroscopy were found.

2) Correlation between appropriateness and colonoscopy findings

The colonoscopy was abnormal in 35 patients (uncomplicated diverticular disease in 15 cases (11\%) and significant colonic lesions in 20 cases (14\%)). Table 5 presents colonoscopy findings according to EPAGE criteria.

It is recognized that appropriateness of colonoscopy was associated with a greater findings of abnormality in colonoscopy ( $p=0.001)$. However, this difference not significant when only included significant lesions ( $\mathrm{p}=$ 0.189).

Colorectal cancers were diagnosed exclusively in appropriate (11\%) and uncertain (5\%) indications groups according to the EPAGE criteria. Cancer prevalence between these two groups was not significant $(p=0.35)$. Adenomas were more often found in appropriate colonoscopy without statistical significant difference (7\% versus $6 \% ; p=0.72$ ).

\section{DISCUSSION}

The EPAGE I criteria were applicable in $91 \%$ of cases in our study. This proportion was recovered by Kmieciak et al. [12] in France in 2001 with the same criteria. In this study (449 colonoscopies), it was 94\% at Cochin Hospital. Comparable numbers were reported by Ballaguer et al. in 2005 (89\% of 350 colonoscopies) [13], work also performed in a university hospital in Spain. This study used the EPAGE II criteria. Carrion et al. based on the EPAGE II criteria had also reported 94\% of applicability [14]. Bosset et al. with a Swiss criteria noted applicability of 96\% [15]. However, Fernández-Esparrach et al. had observed a rather smaller proportion (80\%) applicable indication with the EPAGE II criteria [16]. However, the sample in this study focused on a set of colonoscopies (n $=478)$ and gastroscopy $(n=264)$ on one hand. Furthermore, indications for colonoscopy were labeled as not applicable comprises the data does not meet the EPAGE II criteria but also unusable files. The main indication for 12 colonoscopies with the EPAGE criteria inapplicable was research of primary tumor in the assessment of colonic liver metastasis (4 cases). As emphasized by Kmieciak et al. [12], in view of the frequency of hepatic metastasis of digestive origin, the importance of histological evidence in therapeutic strategy and the therapeutic impact of a primary colonic tumor, this indication was a legitimate practice even if this scenario was not among the information retained by EPAGE. Note that the criteria defined by EPAGE were established to evaluate the appropriateness of colonoscopy in screening for colorectal cancer and not in the diagnosis approach to a given situation.

In our study, indications for colonoscopy were appropriate in $40 \%$ of cases $(\mathrm{p}=0.03)$. Burnand et al. [17] had found a lower number of appropriate indications. In their study, uncertain indications according to the EPAGE criteria were most frequently. Their study had the particularity to be composed only by colonoscopy for colorectal cancer screening, which was not reported in our work. In other studies using or not the EPAGE criteria, appropriateness of colonoscopy was higher than in our study. Thus to Kmieciak et al. [12] using the EPAGE I criteria, this proportion was 54\%. In order to respectively Carrión [14] Fernández-Esparrach [16], and Terraz [18] based on the EPAGE II criteria, appropriate indications were 70\%, 69\% and 59\%. According to Coriat et al. [19] using the criteria of ANAES 2004, the appropriateness of colonoscopies was 55\%. Using the reference of the ASGE, Siddique [20], Jabar [21] and Chan [22] respectively reported numbers of $64 \%, 84 \%$ and $57.9 \%$. The main factors according to several authors $[13,16,19,23]$

Table 5. Colonoscopies findings.

\begin{tabular}{|c|c|c|c|c|}
\hline Observed lesions & $\begin{array}{l}\text { Appropriate indication } \\
\qquad(\mathrm{n}=56)\end{array}$ & $\begin{array}{l}\text { Uncertain indications } \\
\qquad(\mathrm{n}=38)\end{array}$ & $\begin{array}{l}\text { Inappropriate indications } \\
\qquad(\mathrm{n}=33)\end{array}$ & $\begin{array}{c}\text { Total } \\
(\mathrm{n}=127)\end{array}$ \\
\hline & n (\%) & n (\%) & n (\%) & n (\%) \\
\hline Abnormal Colonoscopy ${ }^{*}$ & $23(41)$ & $9(24)$ & $2(6)$ & $34(27)$ \\
\hline Colonic diverticulosis & $12(21)$ & $3(8)$ & $0(0)$ & $15(12)$ \\
\hline hyperplasic polyp & $1(2)$ & $0(0)$ & $0(0)$ & $1(1)$ \\
\hline Adenoma with mild dysplasia & $4(7)$ & $2(5)$ & $1(3)$ & $7(5)$ \\
\hline Adenoma with severe dysplasia & $0(0)$ & $0(0)$ & $1(3)$ & $1(1)$ \\
\hline Ulcerative colitis & $0(0)$ & $2(5)$ & $0(0)$ & $2(2)$ \\
\hline Cancer & $6(11)$ & $2(5)$ & $0(0)$ & $8(6)$ \\
\hline
\end{tabular}

${ }^{*} \mathrm{p}=0.001$. 
influencing the proportion of appropriate colonoscopy were patients older age, specialty of gastroenterologist and indication of the colonoscopy itself. Indications most often associated with the appropriateness of colonoscopy were rectal bleeding [24], assessment of iron deficiency anemia [24]; surveillance after resection of polyps or colorectal cancer [25] and colorectal cancer screening [26]. The patients in our study were younger compared with those of these studies and there was no indication of colorectal cancer screening or surveillance after resection of colorectal cancer. The lack of monitoring of patients operated for colorectal cancer and the low prevalence of this cancer in Côte d'Ivoire (3\% - 4\% [3-6]) could explain this fact. As in these studies, gastroenterologists were the most numerous prescribers of appropriate colonoscopy according to the EPAGE criteria in our work.

Applying the EPAGE criteria, 24\% of the 139 colonoscopies in our series were deemed inappropriate. Balaguer et al. [13] using EPAGE II criteria noted also that $23 \%$ of 312 colonoscopies were inappropriate. In this study, there was a correlation between referring physician, patient age and appropriateness of colonoscopy. Kmieciak et al. [12] with the EPAGE I criteria had noted that $6 \%$ of colonoscopies were inappropriate. Numbers as low as were also seen by Coriat using the ANAES 2004 criteria (7\%) [19] and Denis (9.7\% of the 500 colonoscopies according to the EPAGE criteria [27]). Proportions of $13 \%$ and $18 \%$ were found in other studies using the EPAGE criteria $[17,18]$. In studies using the referential of the ASGE (American society of gastroenterology), results were also variable. Thus, according to Chan [22], 12.9\% of 380 colonoscopies were inappropriate. Siddique [20] Bersani [28] and Morini [29] were reported respectively $20 \%, 37 \%$ and $29 \%$ of inappropriate colonoscopy on ASGE criteria. A study relied on the criteria of a Swiss panel found from Bosset et al. 13\% of inappropriate colonoscopy [15]. Several factors have been identified in these studies, as influencing the proportion of inappropriate indication in their studies. This was indication of the colonoscopy itself, specialty of the prescriber and patient age. In our study, patients assigned to inappropriate EPAGE criteria had following profile: sex ratio 1.06, mean age 36 years, prevalence of bowel habits and abdominal pain, scarcity of colonic abnormalities (8.33\% of abnormal colonoscopy). This profile was suggestive of irritable bowel syndrome. According to several authors, these symptoms were more frequent in inappropriate groups due to the fact that these patients deemed anxious, have often already made several consultations and symptomatic treatments. They want colonoscopies which adheres the gastroenterologist for psychological reasons (to reassure the patient) and forensic (avoid a hypothetical loss of opportunity to the patient). Schüssele et al. [30], with a systematic review of the lit- erature showed that when no signs of alarm and any history of colorectal cancer were found, these functionallike symptoms were associated with a low appropriateness score.

Colonic lesion was found in $25 \%$. When we were interested only to significant lesions (excluding uncomplicated diverticulosis) as in most studies, it was only $14 \%$. The latter number was found by Burnand et al. [17] from colonoscopies performed in patients admitted exclusively for colorectal cancer screening, which was none indication in our work. In most other studies [14,19-21,27-29,31] using or not the EPAGE criteria , proportion of significant lesions was higher in the order of $23 \%$ to $45 \%$. The largest proportion of colonoscopy with inappropriate EPAGE criteria in our study could be the main reason. Because in several studies [13,16,19-22,31], there was a link between appropriateness of colonoscopy and significant lesion. This relationship was still observed in the study of Kmieciak (EPAGE I criteria [12]) nor in that of Chan (ASGE criteria [22]). In the study of Chan et al., only indication of rectal bleeding in multivariate analysis was predictive for colonic lesions. The fact that gastroenterologist [20,23], male sex [15,31], exploration of iron deficiency anemia [14] or rectal bleeding [24] and older age of patients [16,31] were factors associated with colonic lesion was also found in several studies. Colonic functional disorders was, in absence of signs of severity (weight loss, anemia, rectal bleeding, nocturnal recurdescence of signs and family history of colorectal cancer) associated to a low diagnosis yield of colonoscopy according to Schüssele et al. [30]. Irritable bowel syndrome was the most frequent indications of our colonoscopies. Our patients were also younger compared to other studies. The application of EPAGE score allowed highlighting a colorectal adenocarcinoma in $6 \%$ of cases only in the appropriate and uncertain groups. This observation was also reported by Kmieciak et al. [12]. In our low colorectal cancer prevalence country, the reference of EPAGE thus 2.

Our work constructed from a sufficient sample showed that colonic abnormalities were correlated to the relevance of colonoscopy one of the main aims of our study. Understanding that the discovery of cancer and colorectal polyps is not correlated to the appropriateness of the colonoscopy requires in our opinion further studies in Africa, an area of low prevalence of colorectal cancer, our study being the first performed on the African continent.

When the indication for colonoscopy is appropriate or uncertain, there was a proportion of coloni lesion (Table 4) consistent with that reported in the literature (24\% $41 \%)$. In these cases, the realization of colonoscopy is justified with regard of the criteria of EPAGE.

When the indication for colonoscopy is inappropriate, 
the physician shall not perform colonoscopy but first follow the algorithm imposed by the criteria of EPAGE for a given symptom. This is what we call to appeal to his medical reasoning appears as a very effective tool for colorectal cancer diagnosis in symptomatic patients without colorectal cancer risk factors. Indeed, frequency of colorectal cancer diagnosis is comparable to that found in studies conducted in areas of high prevalence, where it varies from $4 \%$ to $9 \%$ [12,31]. Although 33 of 139 colonoscopies (24\%) had an inappropriate indication according to EPAGE criteria in our study, 2 patients had significant lesions (one adenoma with mild dysplasia and severe dysplasia in an adenoma). This observation was also found by Kmieciak et al. [12]. This team reported that 25 patients whose colonoscopy was inappropriate according to the EPAGE criteria three had adenomas (one with an outbreak of severe dysplasia). The choice to perform a colonoscopy in an individual patient can not only depend on the appropriateness or not of colonoscopy. The diagnostic approach of the physician must also be considered. This underlines importance of collaboration between practitioners in patient's care. Finally, Terraz et al. [18] showed that the site of the EPAGE was easy to use, intuitive and quickly accessible.

\section{CONCLUSION}

Following this prospective study at the university hospital in Cocody, the results indicate that the EPAGE criteria are applicable. According to them, Colonoscopies had significantly appropriate. Polyps and colorectal cancers, however, were not correlated with appropriateness of colonoscopy. Therefore, the EPAGE criteria cannot replace to medical reasoning but should be for the practitioner a useful tool to help. However, in our developing country the difficulty of access to internet could hamper its extension.

\section{REFERENCES}

[1] Attia, Y., Soubeyand, J., Beda, Y., et al. (1981) Place de la pathologie colique en milieu Africain. Médecine d'Afrique Noire, 28, 349-351.

[2] Camara, B.M., N'dri, N., Lombardo, A., et al. (1991) Eléments d'épidémiologie de la pathologie colique du noir Africain en milieu hospitalier en Côte d'Ivoire. Médecine et Chirurgie Digestive, 20, 449-452.

[3] Attia, Y., Soubeyrand, J., Gaudet, D., et al. (1981) Les cancers coliques en Côte d'Ivoire: Etude clinique et épidémiologique. Médecine d'Afrique Noire, 28, 353-358.

[4] Manlan, K., Gaudet, D., Carsuzaa, M., et al. (1983) Détection des polypes et des cancers rectocoliques dans une population d'hospitalisés et de consultants au CHU de Cocody. Revue médicale de Côte d'Ivoire, 61,14-18.

[5] Camara, B.M., Malan, K.L. and Attia, Y.R. (1986) Aspects épidémiologiques des cancers du colon chez le noir africain en Côte d'Ivoire. Afrique Médecine Santé, 7, 1013.

[6] Assi, C., Nigué, L., Camara, B.M., et al. (2004) Polypes et adénocarcinomes colorectaux en milieu tropical: Quels liens épidémiologiques et endoscopiques? Afrique Biomédicale, 9, 52-56.

[7] ANAES (1998) Conférence de consensus: Prévention, dépistage et prise en charge des cancers du côlon. Gastroentérologie Clinique et Biologique, 22, 219-226.

[8] Pheli, J.M., Milan, C., Herbert, C., et al. (2004) Evaluation of the management of colo-rectal cancers before and after the consensus conference in France. European Journal of Gastroenterology and Hepatology, 16, 1003-1009. doi:10.1097/00042737-200410000-00009

[9] Crispin, A., Birkner, B., Munte, A., et al. (2009) Process quality and incidence of acute complications in a series of more than 230,000 outpatient colonoscopies. Endoscopy, 41, 1018-1025. doi:10.1055/s-0029-1215214

[10] Condon, A., Graff, L., Elliot, L. and Ilnyckyj, L. (2008) Acceptance of colonoscopy require most than test tolerance. Canadian Journal of Gastroenterology, 22, 41-47.

[11] Vader, J.P., Froehlich, F., Dubois, R.H., et al. (1999) The European Panel on the appropriateness of gastrointestinal endoscopy (EPAGE): Conclusion and www site. Endoscopy, 8, 687-694. doi:10.1055/s-1999-72

[12] Kmieciak Le Corguille, M., Gaudric, M., et al. (2003) Pertinence des indications de la coloscopie dans un service de gastroentérologie de l'AP-HP en 2001. Gastroenterologie Clinique et Biologique, 27, 213-218.

[13] Balaguer, F., Llach, J., Castells, A., et al. (2005) The European panel on the appropriateness of gastrointestinal endoscopy guidelines colonoscopy in an open-access endoscopy unit: A prospective study. Alimentary Pharmacology \& Therapeutics, 21, 609-613. doi:10.1111/j.1365-2036.2005.02359.x

[14] Carrión, S., Marín, I., Lorenzo-Zúñiga, V., et al. (2010) Appropriateness of colonoscopy indications according to the new EPAGE II criteria. Journal of Gastroenterology and Hepatology, 33, 484-489. doi:10.1016/j.gastrohep.2010.05.003

[15] De Bosset, V., Froehlich, F., Rey, J.P., et al. (2002) Do explicit appropriateness criteria enhance the diagnostic yield of colonoscopy? Endoscopy, 34, 360-368. doi:10.1055/s-2002-25277

[16] Fernández-Esparrach, G., Gimeno-García, A.Z., Llach, J., et al. (2007) Guidelines for the rational use of endoscopy to improve the detection of relevant lesions in an openaccess endoscopy unit: A prospective study. Medicina Clínica, 129, 205-208. doi:10.1157/13107917

[17] Burnand, B., Harris, J.K., Wietlisbach, V., et al. (2006) Use, appropriateness, and diagnostic yield of screening colonoscopy: An international observational study (EPAGE). Gastrointestinal Endoscopy, 63, 1018-1026. doi:10.1016/j.gie.2006.01.051

[18] Terraz, O., Wietlisbach, V., Jeannot, J.G., et al. (2005) The EPAGE internet guideline as a decision support tool for determining the appropriateness of colonoscopy. Digestion, 71, 72-77. 
[19] Coriat, R., Pommaret, E., Chryssostalis, A., et al. (2009) Quality control of colonoscopy procedures: A prospective validated method for the evaluation of professional practices applicable to all endoscopic units. Gastroenterologie Clinique et Biologique, 33, 103-108. doi:10.1016/j.gcb.2008.04.038

[20] Siddique, I., Mohan, K., Hasan, F., et al. (2005) Appropriateness of indication and diagnostic yield of colonoscopy: First report based on the 2000 guidelines of the American Society for Gastrointestinal Endoscopy. World Journal of Gastroenterology, 11, 7007-7013.

[21] Jabar, M.F., Halim, M.E. and Gul, Y.A. (2004) Appropriateness of colonoscopy in a tertiary referral centre. Asian Journal of Surgery, 27, 26-31. doi:10.1016/S1015-9584(09)60240-2

[22] Chan, T.H. and Goh, K.L. (2006) Appropriateness of colonoscopy using the ASGE guidelines: Experience in a large Asian hospital. Chinese Journal of Digestive Diseases, 7, 24-32. doi:10.1111/j.1443-9573.2006.00240.X

[23] Tan, Y.M. and Goh, K.L. (2004) Appropriateness of colonoscopy in a university hospital. Medical Journal of Malaysia, 59, 34-38.

[24] Peytremann-Bridevaux, I., Arditi, C., Froehlich, F., et al. (2009) EPAGE II study group. Appropriateness of colonoscopy in Europe (EPAGE II). Iron-deficiency anemia and hematochezia. Endoscopy, 41, 227-233. doi:10.1055/s-0028-1119644

[25] Arditi, C., Gonvers, J.J., Burnand, B., et al. (2009) EPAGE II study group. Appropriateness of colonoscopy in Europe (EPAGE II). Surveillance after polypectomy and after resection of colorectal cancer. Endoscopy, 41, 209-217. doi:10.1055/s-0028-1119646

[26] Arditi, C., Peytremann-Bridevaux, I., Burnand, B., et al. (2009) EPAGE II study group. Appropriateness of colonoscopy in Europe (EPAGE II). Screening for colorectal cancer. Endoscopy, 41, 200-208. doi:10.1055/s-0028-1119626

[27] Denis, B., Weiss, A.M., Peter, A., et al. (2004) Quality assurance and gastrointestinal endoscopy: An audit of 500 coloscopic procedures. Gastroenterologie Clinique et Biologique, 28, 1245-1255. doi:10.1016/S0399-8320(04)95218-9

[28] Bersani, G., Rossi, A., Ricci, G., et al. (2005) Do ASGE guidelines for the appropriate use of colonoscopy enhance the probability of finding relevant pathologies in an open access service? Digestive and Liver Disease, 37, 609-614. doi:10.1016/j.dld.2005.03.008

[29] Morini, S., Hassan, C., Meucci, G., et al. (2001) Diagnostic yield of open access colonoscopy according to appropriateness. Gastrointestinal Endoscopy, 54, 175-179. doi:10.1067/mge.2001.116565

[30] Schusselé, F.S., Juillerat, P., Burnand, B., et al. (2009) EPAGE II study group. Appropriateness of colonoscopy in Europe (EPAGE II). Chronic diarrhea and known inflammatory bowel disease. Endoscopy, 41, 218-226.

[31] Gonvers, J.J., Harris, J.K., Wietlisbach, V., et al. (2007) EPAGE study group. A European view of diagnostic yield and appropriateness of colonoscopy. Hepatogastroenterology, 54, 729-735. 